\title{
Ambient temperature as a determinant of landscape use in the savanna elephant, Loxodonta africana
}

\author{
A.A. Kinahan ${ }^{a}$, S.L. Pimm ${ }^{a, b}$ and R.J. van Aarde \\ ${ }^{a}$ Department of Zoology and Entomology, Conservation Ecology Research Unit, \\ University of Pretoria, Pretoria 0002, South Africa \\ ${ }^{b}$ Nicholas School of the Environment and Earth Sciences, Duke University, North \\ Carolina, NC, USA
}

\begin{abstract}
Elephants occur in landscapes where temperatures can reach $50^{\circ} \mathrm{C}$. Due to their large size they may face physiological problems of dissipating heat during such high temperatures. In spite of this, no one seems to have considered ambient temperature as limiting landscape choices in elephants. We recorded hourly landscape use in freeranging elephants using GPS collars. We also placed temperature data loggers in each of the landscapes, to obtain corresponding ambient temperatures for each hour. Our results suggest that elephants may select landscapes based on the rate at which temperatures changed and also for shade. We suggest that these selected variables provide a thermal benefit to individuals. As such, we propose that landscape use in elephants may be constrained by their thermal physiological requirements as well as other resources such as food and water.
\end{abstract}

\section{Article Outline}

1. Introduction

2. Material and methods

2.1. Study area

2.2. Data collection 
2.3. Data analyses

3. Results

3.1. Temperature selection

3.2. Landscape selection

3.3. Temperature changes in landscape preferences

4. Discussion

5. Conclusion

Acknowledgements

References

\section{Introduction}

In savannas, temperature extremes during summer (up to $50^{\circ} \mathrm{C}$; Cole, 1986) and winter (below $0{ }^{\circ} \mathrm{C}$ at night; Scholes and Walker, 1993) are well outside that of the normal body temperature of an elephant, Loxodonta africana $\left(36.4^{\circ} \mathrm{C}\right.$; Buss and Wallner, 1965). Consequently, elephants living in such savannas may face several thermoregulatory problems, exacerbated by their large size. Metabolic heat production scales with body mass (McNab, 1983) and large-bodied species have smaller surface area to volume ratios than smaller species. Larger mammals, therefore, have relatively small areas available for heat transfer compared to small mammals (Williams, 1990). For that reason large mammals will lose heat slower than smaller mammals during periods of environmental heat stress. Based on size alone, therefore, free-ranging elephants in savannas may encounter problems dissipating heat, particularly during spells of extremely high ambient temperatures. To date, all studies on thermoregulation in elephants have been limited to captive individuals only (e.g. Wright and Luck, 1984, Williams, 1990, Phillips and Heath, 1992) and during temperatures far below those that they may experience in the wild. While studies on captive elephants aid our understanding of their thermoregulation, we are not aware of any studies that have examined the role that thermoregulation may play in elephant ecology.

Elephants may use their ears as 'thermal windows' (Phillips and Heath, 1992) and, although they do not 'sweat', they do facilitate cooling by the evaporation of water through their skin (Wright and Luck, 1984). In addition, high thermal conductance (the 
ease in which heat is exchanged between an animal and its environment; e.g. McNab, 1983 ) in elephants may counteract reduced heat transfer that is associated with their size (Williams, 1990). Elephants may overcome some of the constraints imposed by their size by selecting landscapes with temperatures that facilitate thermoregulation during daily spells of temperature extremes. In the past, resources such as food availability (Dublin, 1996), water (Verlinden and Gavor, 1998; De Boer et al., 2000; Stokke and du Toit, 2002), nutrients (Ruggiero and Fay, 1994; Houston, et al., 2001), rugged terrain (Nellemann et al., 2002) and human habitation (Hoare, 1999) have all been linked to landscape selection in the elephant. However, despite ambient temperature affecting the activity levels of elephants (Ndumo, 1977), no studies have attempted to explore the possible role ambient temperature may also have on influencing landscape utilization by elephants.

We examined the influence of ambient temperature in different landscapes on the hourly landscape-use patterns in two free-ranging elephant populations. We calculated the hourly rate at which temperatures changed across the landscapes to determine how landscapes were warming up or cooling down relative to each other. We assumed that free-ranging elephants aim to maintain a relatively stable core body temperature at all environmental temperatures. For heat exchange to occur, a gradient must exist between the surface temperature of an individual and its environment (Tracy, 1972). If the ambient temperature $\left(T_{\mathrm{a}}\right)$ is lower than the surface temperature of an animal $\left(T_{\mathrm{s}}\right)$, then the animal is likely to lose heat to its environment (Tracy, 1972). Increasing the difference between the $T_{\mathrm{a}}$ and $T_{\mathrm{s}}$ will incur a greater heat loss from the animal to its environment for species, which maintain stable body temperatures. Thus, at ambient temperatures below the surface temperature of an animal, the faster the ambient temperature decreases, the quicker the animal is likely to lose heat to its environment. Similarly, as ambient temperature increases (at $T_{\mathrm{a}}<T_{\mathrm{s}}$ ), heat loss from an individual to its environment will decrease. In situations where $T_{\mathrm{a}}>T_{\mathrm{s}}$, the same principles apply except in this instance, increasing or decreasing an animals heat gain from their environment.

We predict, therefore, that being homeotherms, if elephants select landscapes facilitating thermoregulation, they should demonstrate selection in the following way: 
(1) During high ambient temperatures, to facilitate heat loss or to reduce heat gain, elephants will select landscapes that cool down faster or warm up slower than those not selected.

(2) During low ambient temperatures to reduce heat loss or to increase heat gain, elephants will select landscapes that will cool down slower or warm up faster than those not selected.

\section{Material and methods}

\subsection{Study area}

We studied free-ranging elephants in the Kafue and Lower Zambezi National Parks in Zambia, herein referred to as Kafue and Zambezi. Kafue $\left(22,400 \mathrm{~km}^{2}\right)$ is in central Zambia ( $14^{\circ} 03^{\prime}-16^{\circ} 43^{\prime} \mathrm{S}$ and $\left.25^{\circ} 13^{\prime}-26^{\circ} 46^{\prime} \mathrm{E}\right)$, is unfenced, and surrounded by Game Management Areas. Our study was in the southern sector of the Park and the surrounding Nkala Game Management Area. There are currently about 1100 elephants in this region (Guldemond et al., 2005). The Lower Zambezi National Park $\left(4092 \mathrm{~km}^{2}\right)$ lies along the Zambezi River $\left(15^{\circ} 36^{\prime}-15^{\circ} 78^{\prime} \mathrm{S}\right.$ and $\left.29^{\circ} 22^{\prime}-22^{\circ} 94^{\prime} \mathrm{E}\right)$. The Park is unfenced but a natural barrier occurs from the escarpment running along the north of the Park. There are about 1500 elephants (Dunham, 2003). Zambia has three seasons: the hot dry season between September and October, the wet season between November and April and the cold dry season occurring between May and August (JICA, 1999).

\subsection{Data collection}

We fitted 10 elephants in Kafue and six in Zambezi with collars containing built-in GPS satellite units (model AWT SM2000E, Africa Wildlife Tracking, Pretoria, South Africa). We followed standardized procedures sanctioned by the ethics committee of the University of Pretoria and the Zambian Wildlife Authority. During the hot dry season in Kafue, all 10 individuals provided data. Our sample size was reduced to eight individuals - four cows and four bulls - for the cold dry season. All six cows in the Zambezi provided data.

Physiognomic characteristics defined landscapes in each of the study areas. These include open areas (grasslands or areas sparsely covered in vegetation), shrublands, open 
woodlands, closed woodlands and thickets. We considered open areas and shrublands as landscapes with little or no canopy coverage, open woodlands to have "medium coverage" and closed woodlands and thickets to have "high canopy coverage". We identified the landscapes elephants used from the IDRISI 32 imaging processing system (Clark Labs, Clark University, Worcester, MA, USA) and classified Landsat 5 TM images (CSIR Satellite Application Centre, Pretoria, South Africa). A maximum likelihood supervised classification generated landscape maps for each of the sites. We verified the accuracy of the classified landscape maps by ground-truthing. In Kafue, during the hot dry season (October 2003), our study lasted for 2 days and nights and for 3 days and nights in the cold dry season (July 2004). We recorded data in the Zambezi for a period of 3 days and nights in the hot dry season (September 2004). HOBO $^{\circledR},(n=21)$, StowAway ${ }^{\circledR}(n=6)$ (C.W. Price and Co (Pty) Ltd) temperature loggers with BOX CAR ${ }^{\circledR}$ software (1992-99 Onset Computer Corporation), and iButton ( $\left.n=50\right)$ data loggers (CST electronics, Johannesburg, South Africa) with iButton-TMEX software version 3.21 (2004 Dallas Semiconductor MAXIM Corporation) recorded ambient temperature at random locations in each of the landscape types. We limited our surveys to the dry seasons, when a limited availability of water may induce thermal challenges. We also collected data in the cold dry season in Kafue only, as a control, since we anticipated no thermal challenges occurring for elephants during this season.

We recorded temperature at hourly intervals during our surveys. Collecting hourly location points reduces the life span of the satellite collars, as such the number of days and nights in which we collected hourly data was limited. Other data collected at $24 \mathrm{~h}$ intervals prior to and after the survey showed that landscape use we observed is typical for each of the seasons. We assumed that conditions prevailing during the survey period, which fell in the middle of each of the seasons, were typical for that season.

Loggers were placed below plastic disks so they were shaded from direct sunlight and secured on $2 \mathrm{~m}$ plastic poles placed over metal stakes. Before fieldwork, we examined any potential differences between the logger types by placing them under similar environmental conditions. The differences between the data loggers were negligible. 


\subsection{Data analyses}

Ward's hierarchal cluster analysis grouped daily time periods based on ambient temperatures and the hourly rate of change in temperatures recorded by each of our loggers. We used $t$-tests to examine differences in ambient temperatures occurring across the sites and seasons, for each of these clustered periods. A one-way repeated measure ANOVA examined whether significance differences occurred between the rates of change available to the elephants, for each of the clustered periods.

We identified the landscape type for each of the location points for elephants from our classified landscape maps. For each hour, we determined the rates at which selected temperatures changed $\left(\Delta T=T_{l, t+1}-T_{l, t}\right.$, where $T_{l, t}$ is the ambient temperature in the selected landscape $l$ at time $t$ and $T_{l, t+1}$ is the ambient temperature in the selected landscape $l$ at time $t+1$ ) (Fig. 1a). The rates of change available to an elephant differed across the landscapes depending on the landscape chosen at time $t$ and the difference between each of the other landscape types at time $t+1$, including the landscape occupied at time $t$. Since availability may be different throughout the day depending on where the elephant was at time $t$, we calculated the available rates of change for each hour individually (Fig. 1b). At any given time period, an elephant had a choice to stay in its present landscape or to move to another. By examining the rates of change in temperatures, we overcome statistical dependence of analyzing the temperatures themselves, for those data are strongly autocorrelated. 


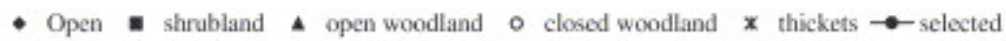
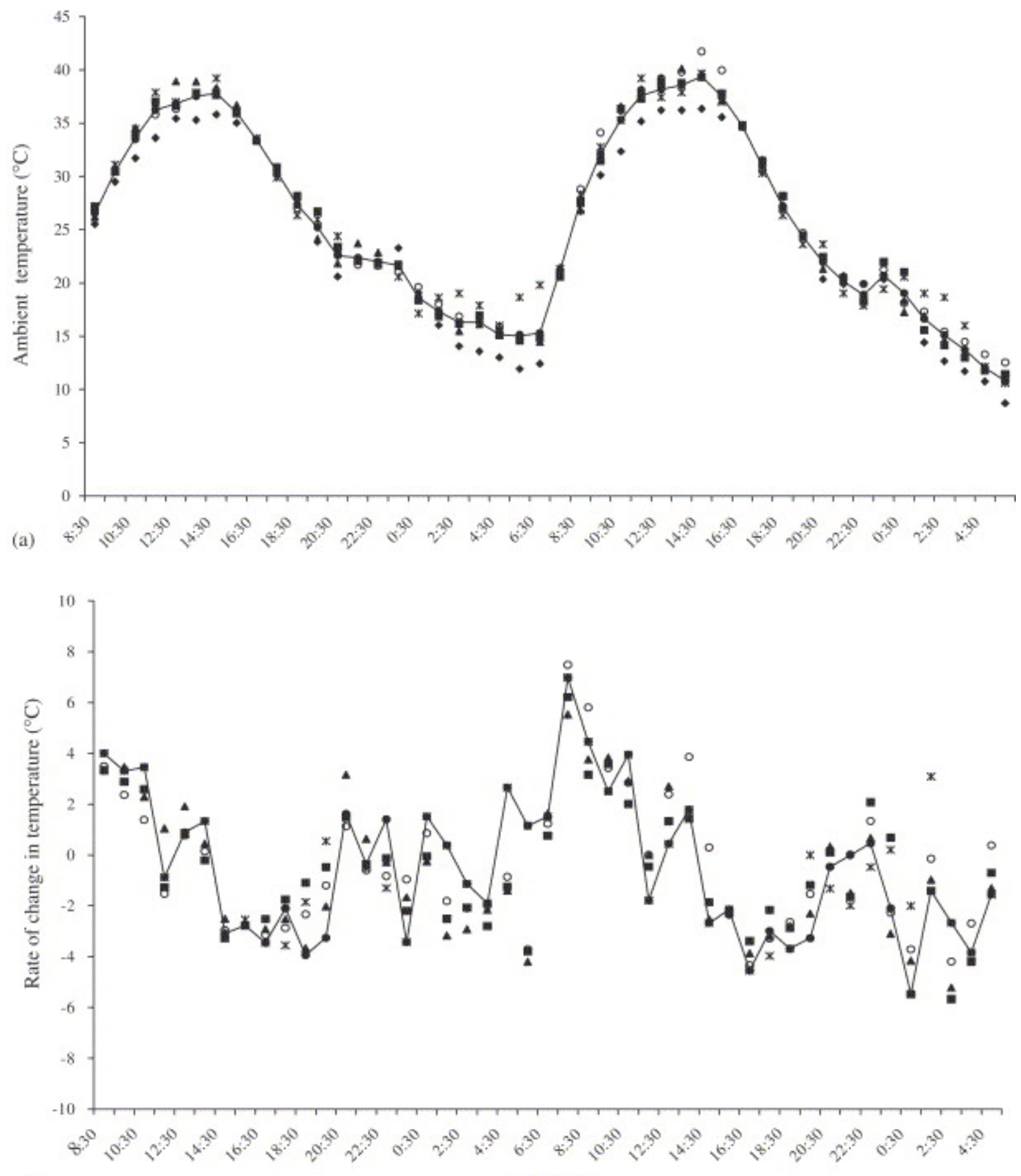

(b)

Hour of Day

Fig. 1. At any given time elephants have a choice of landscapes with different ambient temperatures $\left(T_{l, t}, T_{l, t+1}, \ldots, T_{l, t+n}\right)$ (a). The rate at which ambient temperature changes to which they are exposed depends on the ambient temperature in their selected landscape at time, $t$ and at time $t+1$. Elephants, therefore, also have a choice of rates of change in 
temperature (b). Each symbol represents the different choices they have in ambient temperatures and in the rates of change in temperature, the solid line represents an example of an individuals' selection in both instances, from those that were available. Linear regression analyses compared rates of change selected by the elephants, with those not selected but were available to the elephant. No differences would occur between selected and non-selected rates of change in temperatures if elephants did not select for temperature. Thus, we inferred selection when significant differences occurred in the slopes or intercepts between those selected and those not selected.

We defined landscape availability as the proportion of each landscape in an individual's home range, calculated using a minimum convex polygon method. A Bonferroni's confidence interval procedure (Neu et al., 1974) established whether an elephant used a landscape more (preferred) or less (avoided) than expected based on its proportion within the home range. To test whether elephants were selecting for rates of change independent of landscape preference, we compared the rate of change in temperatures in preferred with avoided landscapes.

\section{Results}

Our results comprise three main sections. First, we consider temperature selection and second landscape selection, each separately. The third analysis looks at temperature selection given the overall landscape preferences of the elephants.

\subsection{Temperature selection}

Rather than group the data into arbitrary times of day (such as morning, afternoon, after dark, before dawn), we employed a formal cluster analysis. In Kafue, in the hot, dry season, for example, the cluster analysis suggested that periods from 8.00 to 12:00, 12:00 to $18: 00,18: 00$ to $00: 00$ and 00:00 to 08:00 were most similar in their hourly temperatures and rates of temperature changes. For other sites and seasons, the divisions were similar, if at slightly different times of day. Given these clusters of times of day, we then asked whether there are statistical differences in the rates of change of temperature across the landscapes. There were, with 
one exception: between 14:00 and 20:00 at Kafue during the cold dry season (Table 1). Only during this interval, were all landscapes changing at the same rate.

Table 1.

Temperature characteristics for time periods defined by cluster analysis

\begin{tabular}{|l|l|l|l|l|}
\hline Hours & Site & Season & $\boldsymbol{T}$ ranges $\left({ }^{\circ} \mathbf{C}\right)$ & $\Delta T$ ranges $\left({ }^{\circ} \mathbf{C} / \mathbf{h}\right)$ \\
\hline $08: 00-10: 00$ & Kafue & Cold dry & $9.5-24.0$ & -6.9 to +14.3 \\
\hline 10:00-14:00 & Kafue & Cold dry & $18.0-37.0$ & -10.4 to +15.5 \\
\hline 14:00-20:00 & Kafue & Cold dry & $10.5-37.0$ & -13.5 to +9.0 \\
\hline 20:00-08:00 & Kafue & Cold dry & $3.5-20.0$ & -10.9 to +12.5 \\
\hline 08:00-12:00 & Kafue & Hot dry & $25.0-41.0$ & -1.8 to +8.2 \\
\hline 12:00-18:00 & Kafue & Hot dry & $29.5-41.0$ & -6.2 to +6.9 \\
\hline 18:00-00:00 & Kafue & Hot dry & $26.0-32.0$ & -6.1 to +4.1 \\
\hline 00:00-08:00 & Kafue & Hot dry & $8.5-29.0$ & -6.9 to +9.1 \\
\hline 07:00-11:00 & Zambezi & Hot dry & $18.0-46.5$ & -0.8 to +12.9 \\
\hline 11:00-17:00 & Zambezi & Hot dry & $30.0-47.5$ & -10.9 to +3.3 \\
\hline 17:00-19:00 & Zambezi & Hot dry & $18.5-38.5$ & -10.2 to +6.7 \\
\hline 19:00-07:00 & Zambezi & Hot dry & $10.5-34.0$ & -13.4 to +14.9 \\
\hline The & Kable & Kaws & & \\
\hline
\end{tabular}

The table also shows the range of temperatures $(T)$ and rates of change in temperatures $(\Delta \mathrm{T})$ across the landscape types occurring for each time period in each site and season. Rates of change can be negative during periods of temperature increases when an individual moves from landscape $x$ with a higher temperature at time $t$, to landscape $y$ where temperatures are lower at $t+1$.

Temperatures generally increased and decreased as expected. They were higher in Zambezi than Kafue during the hot dry season, in the afternoons $(t=5.86, \mathrm{df}=33$, 
$P<0.001)$ and throughout the night $(t=4.36, \mathrm{df}=57, P<0.001)$. Similarly, in Kafue, temperatures during the hot dry season were higher than in the cold dry season, during the day $(t=4.92, \mathrm{df}=16, P<0.001)$ and at night $(t=6.10, \mathrm{df}=46, P<0.001)$.

In both sites and seasons, elephants apparently selected landscapes in terms of the rates at which temperatures changed. Table 2 gives the summary statistics and compares slope and intercept values between selected and non-selected rates of change in ambient temperature.

Table 2.

Table showing differences between selected and the weighted mean non-selected rates of change in temperature

\begin{tabular}{|c|c|c|c|c|}
\hline Time pcriod & Site and $s \in x$ & Scasen & Slope $\beta_{11}$ & Intgrespt $f_{n}$ \\
\hline 0850-10:00 & Kafue sews & Cold dry & $0.9 \pm 0.09$ & $0.2 \pm 0.4$ \\
\hline $1000-14000$ & Kalue sous & Cold dry & $1.9+0.11$ & 204051 \\
\hline $14: 00-20=00$ & Kafue ceoss & Cold dry & $1.0 \pm 0.12$ & $-0.7 \pm 0.44$ \\
\hline 20900-05:09 & Kafue sows & Gold dry & $0.3 \pm 0.99$ & $-0.3 \pm 0.28$ \\
\hline $00: 00-1000$ & Katue bulls & Cokl dry & $0.7 \pm 0.11$ & $1.2+0.0 \%$ \\
\hline $10000-14.00$ & Kafue bulls & Cold dry & $0.5 \pm 0.11$ & $1.3 \pm 0.44$ \\
\hline $1400-20=00$ & Kafue byolls & Cold dry & $1.1 \pm 0.98$ & $-0.33 \pm 0.29$ \\
\hline 20:00-05:00 & Kafue bulls & Cold dry & $0.4 \pm 0.09$ & $-0.5 \pm 0.16$ \\
\hline $08+00-12=00$ & Kalue cows & Het dry & $0.8 \pm 0.11$ & $2.0 \pm 0.35$ \\
\hline $12400-15 \div 00$ & Kalue seass & Hot dry & $09+0.1$ & $0.5 \pm 0.24$ \\
\hline 18:00-00:00 & Kafue ceos & Hot dry & $0.9 \pm 0.09$ & $-0.6 \pm 0.19$ \\
\hline $0000-05=00$ & Kafle cous & Hot dy & $06 \pm 0.09$ & $-0.1 \pm 0.25$ \\
\hline $06000-12=00$ & Kafue bulls & Het dry & $09+0.11$ & $1.3+036$ \\
\hline $12: 00-18000$ & Kafue bulls & Het dry & $1.0 \pm 0.11$ & $0.1 \pm 0.22$ \\
\hline $1800-00=00$ & Kafue linulls & Hex dry & $1.1+0.08$ & $0.2 \pm 0.18$ \\
\hline 00000- $05-60$ & Kafue bulls & Het dry & $09 \pm 0.06$ & $-0.16 \pm 0.18$ \\
\hline $67500-11=00$ & Zambezi conss & Het dry & $0.3 \pm 0.13$ & $3,0 \pm 09$ \\
\hline $11900-1700$ & Zamberi soves & Hot dry & $08 \pm 0.09$ & $=0.9 \pm 0.17$ \\
\hline $17=012-18-60$ & Zambezi eomes & Het dry & $-0.6 \pm 0.36$ & $-6.5 \pm 1.08$ \\
\hline $1900-0>00$ & Zambezi comes & Het dry & $0.3 \pm 0.97$ & $-3.1 \pm 0.17$ \\
\hline
\end{tabular}

$t$-values represent comparisons between selected and non selected slopes $( \pm \mathrm{se})$ and intercepts $( \pm \mathrm{se})$.

Significant at $* P<0.05 ; * * P<0.01 ; * * * P<0.001$.

During the cold season in Kafue, cows and bulls selected for rates of temperature change in all periods except between 14:00 and 20:00, when no choice was available and between 08:00 and 10:00 in cows (Fig. 2). Between 08:00 and 14:00 bulls selected 
landscapes that warmed up slower than those not selected. Cows demonstrated a similar selection pattern between 10:00 and 14:00 only. At night, both cows and bulls selected habitats that cooled down and warmed up slower than those that where not selected.

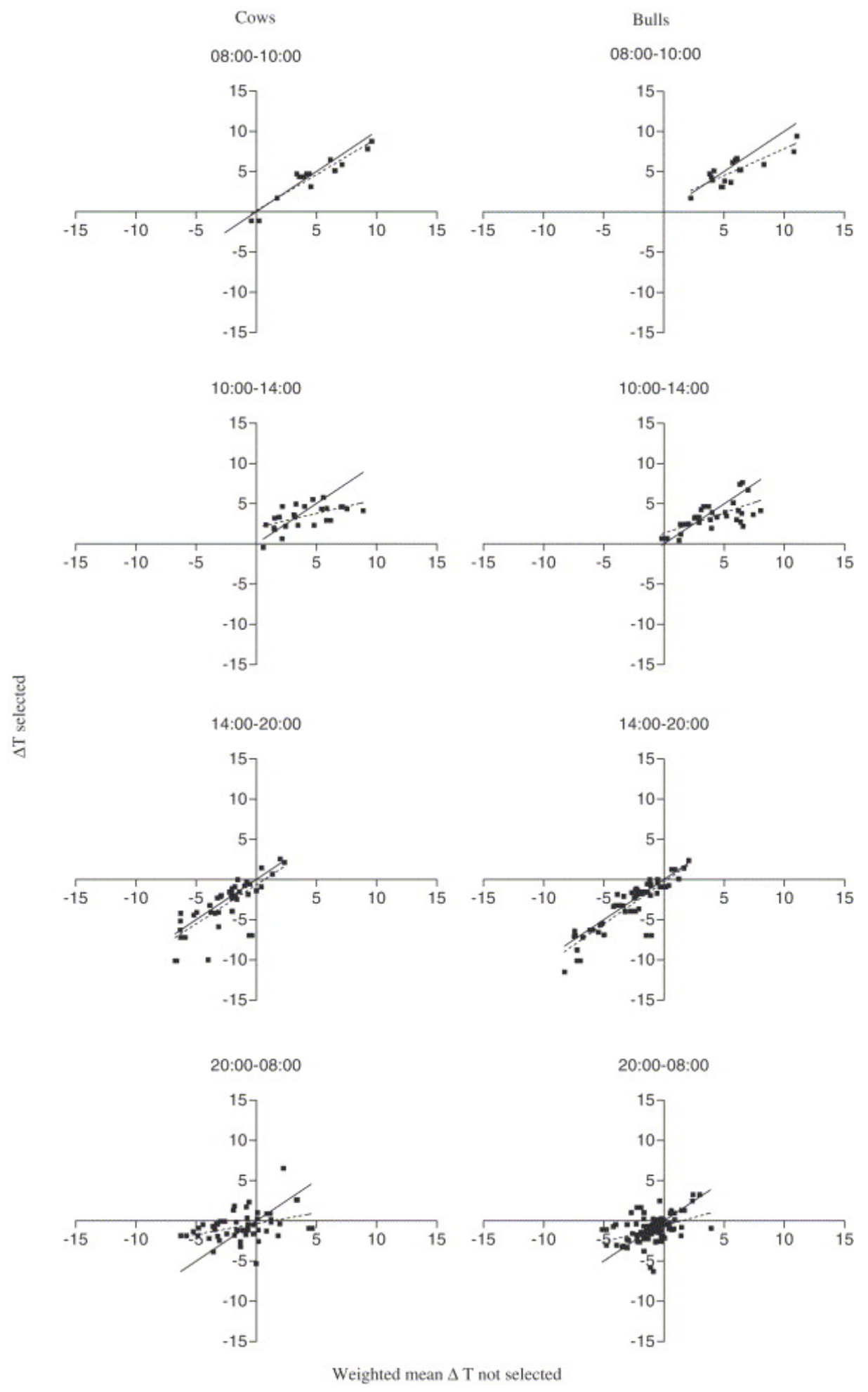


Fig. 2. Comparisons between selected rates of change (stippled line) and those not selected (solid line) by individuals in Kafue during the cold dry season. Using linear regression, we compared the slopes and intercepts for time periods defined by Wards cluster analysis.

In Kafue, during the hot dry season, cows and bulls selected landscapes that warmed faster than landscapes not selected between 08:00 and 12:00. Neither cows nor bulls demonstrated selection for the rate at which temperatures changed throughout the heat of the day between 12:00 and 18:00. Between 18:00 and 00:00, cows only selected landscapes cooling faster and warming slower than those they did not select. Between 00:00 and 08:00, bulls did likewise. However, during this time cows selected landscapes that cooled and warmed slower (Fig. 3) than those they did not select. 

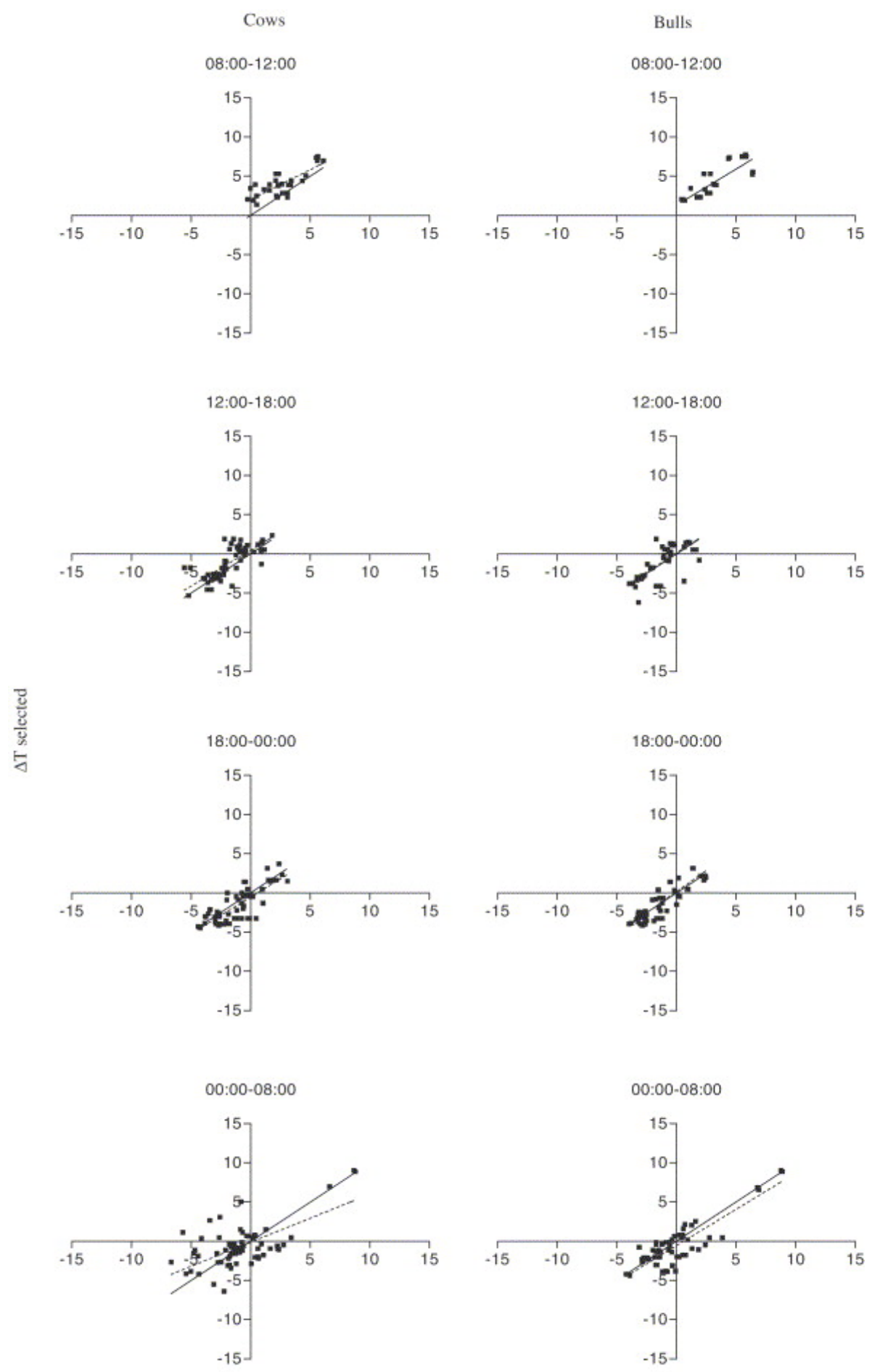

Weighted mean $\Delta \mathrm{T}$ not selected

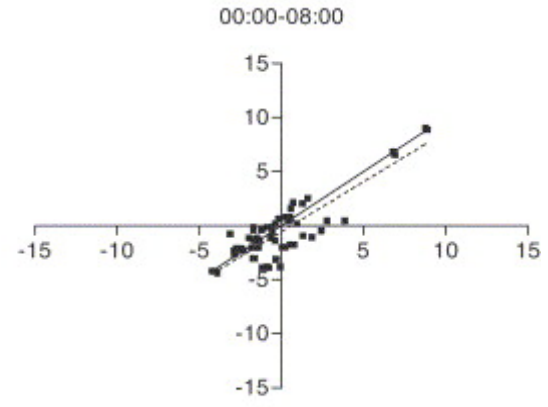

Fig. 3. Comparisons between selected rates of change (stippled line) and those not selected (solid line) by individuals in Kafue during the hot dry season. As in the cold dry 
season, we compared slopes and intercepts for time periods defined by Wards cluster analysis.

Cows in Zambezi selected for the rates of temperature change throughout the day during the hot dry season. Similar to the Kafue individuals during the cold season, those in Zambezi also selected environments that warmed slower but cooled faster than those they did not select.

Between 17:00 and 19:00 cows in Zambezi selected landscapes that cooled faster. Throughout the night, similar to Kafue cows in both seasons, the Zambezi individuals also selected landscapes where the rate of change in temperature was slower than those they did not select (Fig. 4).

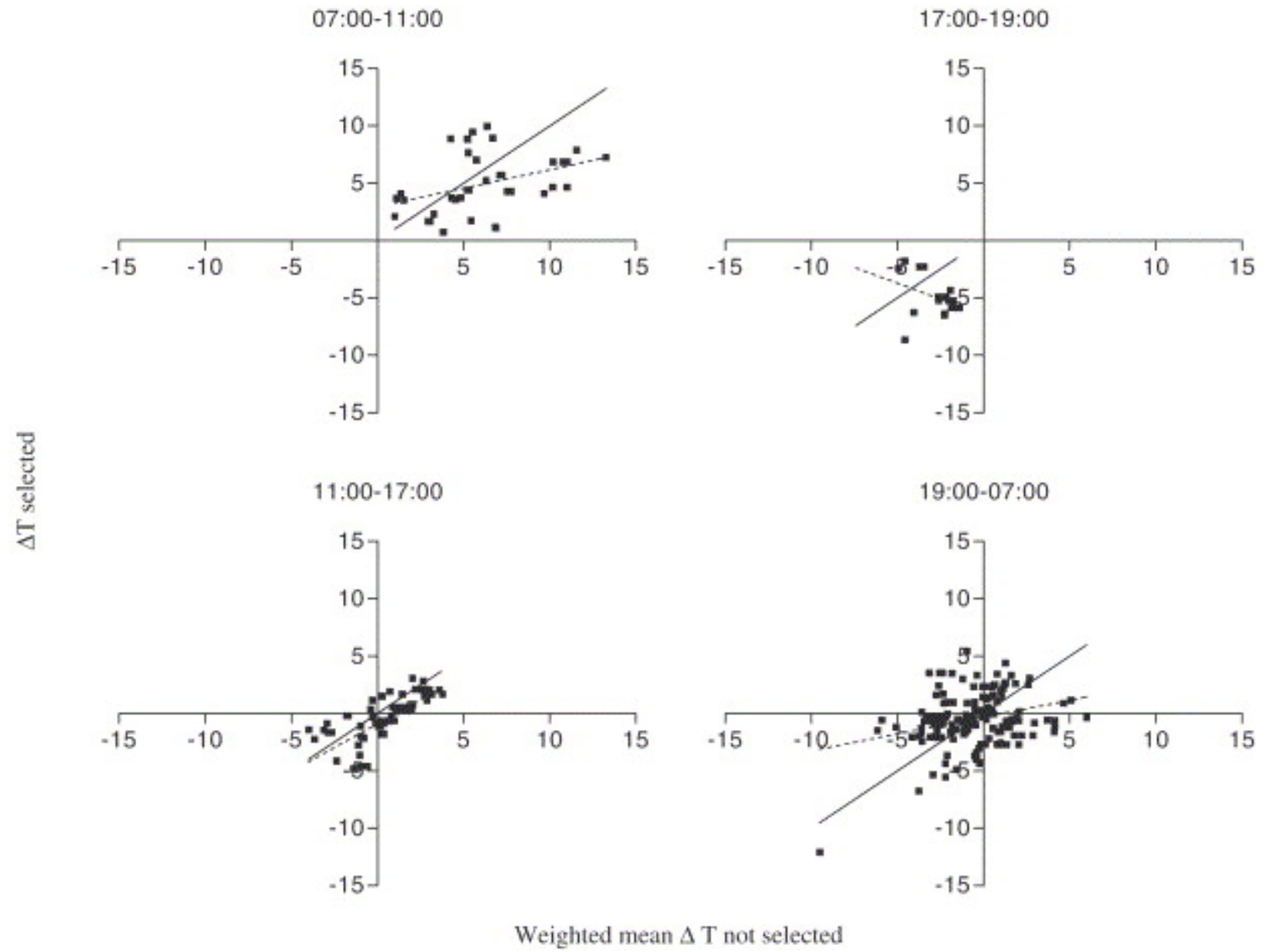

Fig. 4. Comparisons between selected rates of change (stippled line) and those not selected (solid line) by cows in the Lower Zambezi in the hot dry season. Time periods were defined by Wards cluster analysis. 


\subsection{Landscape selection}

Season, site and sex-influenced landscape preference. Elephants did not use all landscapes evenly throughout the day. Table 3 shows the data for those time-periods when elephants did not use landscapes in direct proportion to their availability within an individual's home range.

Table 3.

Bonferroni's confidence intervals (CI) for sites, seasons and time intervals where $\chi^{2}$ analyses indicated selection

\begin{tabular}{|c|c|c|c|c|c|c|}
\hline Time & Site and sex & Season & Landscape type & $P_{0}$ & $\boldsymbol{P}_{\mathrm{e}}$ & $\begin{array}{l}\text { Bonferroni's } \\
\text { CI }\end{array}$ \\
\hline \multirow[t]{4}{*}{ 08:00-10:00 } & Kafue bulls & Cold dry & Open areas & 0.05 & 0.25 & $-0.07-0.16$ \\
\hline & & & Open woodland & 0.43 & 0.59 & $0.16-0.69$ \\
\hline & & & Closed woodland & 0.38 & 0.05 & $0.12-0.64$ \\
\hline & & & Thicket & 0.14 & 0.11 & $-0.04-0.33$ \\
\hline \multirow[t]{4}{*}{$10: 00-14: 00$} & Kafue bulls & Cold dry & Open areas & 0.10 & 0.25 & $0.02-0.18$ \\
\hline & & & Open woodland & 0.44 & 0.59 & $0.30-0.57$ \\
\hline & & & Closed woodland & 0.27 & 0.05 & $0.15-0.39$ \\
\hline & & & Thicket & 0.20 & 0.11 & $0.09-0.30$ \\
\hline \multirow[t]{4}{*}{ 20:00-08:00 } & Kafue bulls & Cold dry & Open areas & 0.52 & 0.25 & $0.48-0.56$ \\
\hline & & & Open woodland & 0.35 & 0.59 & $0.31-0.39$ \\
\hline & & & Closed woodland & 0.09 & 0.05 & $0.06-0.11$ \\
\hline & & & Thicket & 0.04 & 0.11 & $0.02-0.06$ \\
\hline \multirow[t]{4}{*}{ 08:00-12:00 } & Kafue cows & Hot dry & Open areas & 0.04 & 0.25 & $-0.04-0.11$ \\
\hline & & & Open woodland & 0.04 & 0.55 & $-0.04-0.11$ \\
\hline & & & Closed woodland & 0.61 & 0.07 & $0.41-0.80$ \\
\hline & & & Thicket & 0.32 & 0.12 & $0.13-0.51$ \\
\hline \multirow[t]{2}{*}{$12: 00-18: 00$} & Kafue cows & Hot dry & Open areas & 0.21 & 0.25 & $0.11-0.30$ \\
\hline & & & Open woodland & 0.08 & 0.55 & $0.02-0.15$ \\
\hline
\end{tabular}




\begin{tabular}{|c|c|c|c|c|c|c|}
\hline Time & Site and sex & Season & Landscape type & $P_{0}$ & $P_{\mathrm{e}}$ & $\begin{array}{l}\text { Bonferroni's } \\
\text { CI }\end{array}$ \\
\hline & & & Closed woodland & 0.40 & 0.07 & $0.28-0.51$ \\
\hline & & & Thicket & 0.31 & 0.12 & $0.20-0.42$ \\
\hline \multirow[t]{4}{*}{ 18:00-23:00 } & Kafue cows & Hot dry & Open areas & 0.73 & 0.25 & $0.62-0.84$ \\
\hline & & & Open woodland & 0.20 & 0.55 & $0.10-0.30$ \\
\hline & & & Closed woodland & 0.00 & 0.07 & $0.00-0.00$ \\
\hline & & & Thicket & 0.07 & 0.12 & $0.00-0.13$ \\
\hline \multirow[t]{4}{*}{ 08:00-12:00 } & Kafue bulls & Hot dry & Open areas & 0.03 & 0.26 & $-0.03-0.08$ \\
\hline & & & Open woodland & 0.03 & 0.57 & $-0.03-0.08$ \\
\hline & & & Closed woodland & 0.85 & 0.06 & $0.72-0.98$ \\
\hline & & & Thicket & 0.10 & 0.12 & $-0.01-0.21$ \\
\hline \multirow[t]{4}{*}{ 12:00-18:00 } & Kafue bulls & Hot dry & Open areas & 0.17 & 0.26 & $0.08-0.25$ \\
\hline & & & Open woodland & 0.28 & 0.57 & $0.18-0.39$ \\
\hline & & & Closed woodland & 0.45 & 0.06 & $0.33-0.57$ \\
\hline & & & Thicket & 0.10 & 0.12 & $0.03-0.17$ \\
\hline \multirow[t]{4}{*}{ 11:00-17:00 } & Zambezi cows & Hot dry & Open areas & 0.05 & 0.22 & $0.02-0.08$ \\
\hline & & & Open woodland & 0.00 & 0.15 & $0.00-0.00$ \\
\hline & & & Closed woodland & 0.77 & 0.37 & $0.71-0.83$ \\
\hline & & & Thicket & 0.18 & 0.26 & $0.12-0.23$ \\
\hline
\end{tabular}

Bold interface indicates a difference between observed values $P_{\mathrm{o}}$ and expected values $P_{\mathrm{e}}$ at a $P<0.05$ significance level. Bold $P_{\mathrm{o}}$ values indicate preferred landscapes whereas bold $P_{\mathrm{e}}$ values imply avoided landscapes. When the expected values fall within the confidence intervals, then the landscape was considered neutral.

In 90

Table $3, P_{\mathrm{o}}$ is the observed proportional use of a given landscape, for each sex, at each site, in each season. Thus, from 08:00 to 10:00, in the cold dry season, at Kafue, bulls spent $5 \%, 43 \%, 38 \%$, and $14 \%$ of their time in open areas, open woodland, closed 
woodland and thickets, respectively. The proportions of each landscape within a bull's home range at this season are $25 \%, 59 \%, 5 \%$ and $11 \%$, respectively. Using a Bonferroni correction, we calculated the confidence intervals for these expected proportions. In the example, Kafue bulls used open areas less and closed woodlands and thickets more, than expected.

At no time of day during the cold season, did Kafue cows prefer one landscape to any other. Between 08:00 and 10:00 $\left(\chi^{2}=12.78, \mathrm{df}=3, P<0.01\right)$ bulls used closed woodlands and thickets or high canopy coverage, more than expected. Between 10:00 and 14:00, they continued to prefer closed woodlands and to avoid open areas and woodlands $\left(\chi^{2}=11.99, \mathrm{df}=3, P<0.01\right)$. Throughout the night between 20:00 and 08:00, bulls alternated between high canopy cover and little or no cover by using both closed woodlands and open areas more than expected, but open woodlands and thickets less than expected $\left(\chi^{2}=14.32, \mathrm{df}=3, P<0.01\right)$.

During the hot dry season, both cows and bulls preferred certain landscapes. Throughout the day, cows (08:00-12:00: $\chi^{2}=30.44, \mathrm{df}=3, P<0.001 ; 12: 00-18: 00: \chi^{2}=23.47, \mathrm{df}=3$, $P<0.001$ ) used high canopy cover (closed woodlands and thickets) more than expected and tended to avoid medium to low coverage (open areas and woodlands). While bulls exhibited a similar pattern $\left(08: 00-12: 00: \chi^{2}=90.31, \mathrm{df}=3, P<0.001 ; 12: 00-18: 00\right.$ : $\left.\chi^{2}=33.05, \mathrm{df}=3, P<0.001\right)$, they did not appear to either prefer or avoid thickets. Only cows demonstrated landscape selection between 18:00-00:00 $\left(\chi^{2}=12.98, \mathrm{df}=3, P<0.001\right)$, where open areas were used higher than expected.

During the hot dry season, Zambezi elephants selected landscapes between 11:00 and 17:00 only $\left(\chi^{2}=13.66, \mathrm{df}=3, P<0.001\right)$. They preferred closed woodlands compared to landscapes with medium or low coverage.

\subsection{Temperature changes in landscape preferences}

During the periods when elephants showed a preference for particular landscapes (Table 3 ), we compared the rates at which temperatures changed between the preferred and avoided landscapes (Fig. 5). Any deviations in slopes or intercepts from our null model were considered differences between preferred and avoided landscapes. Significant differences occurred during the cold season in Kafue between 10:00 and 14:00 and 20:00 
and 08:00. Between 12:00 and 18:00, in Kafue during the hot dry season and between 11:00 and 17:00 in Zambezi.

Kafue bulls- Cold dry season

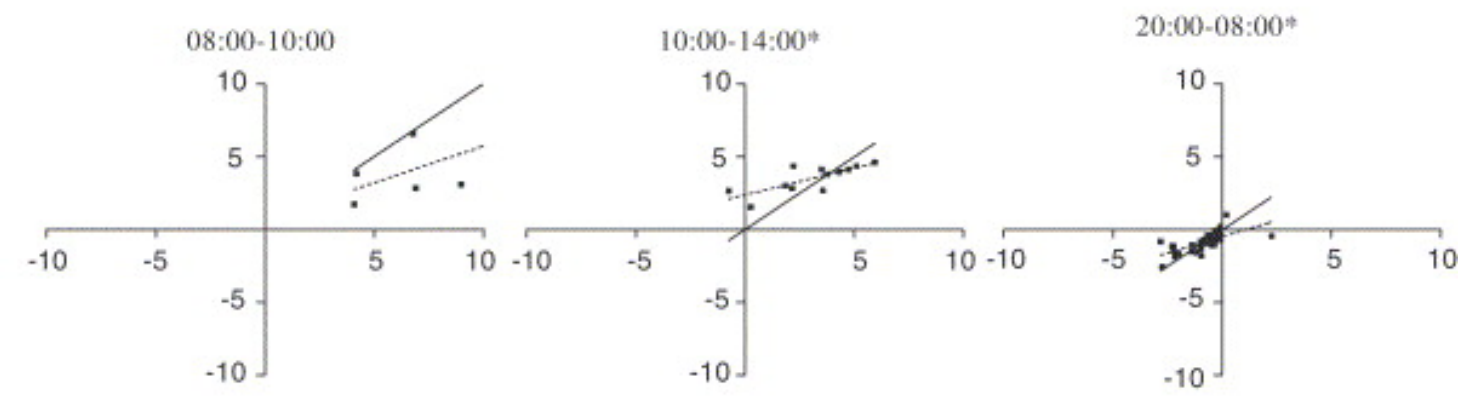

Kafue Cows- Hot dry season

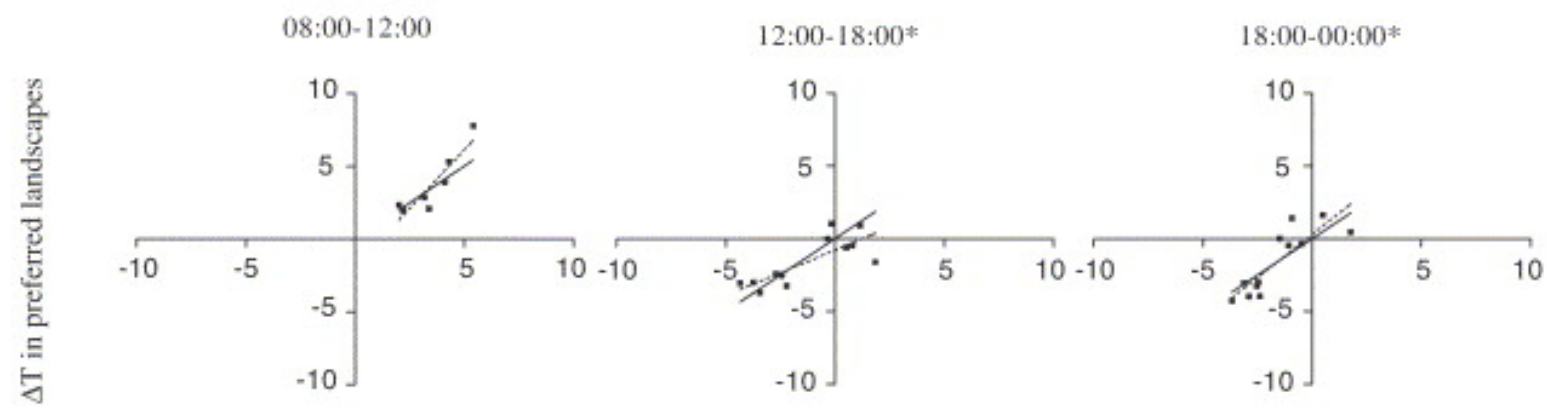

Kafue bulls-Hot dry season Lower Zambezi- Hot dry season

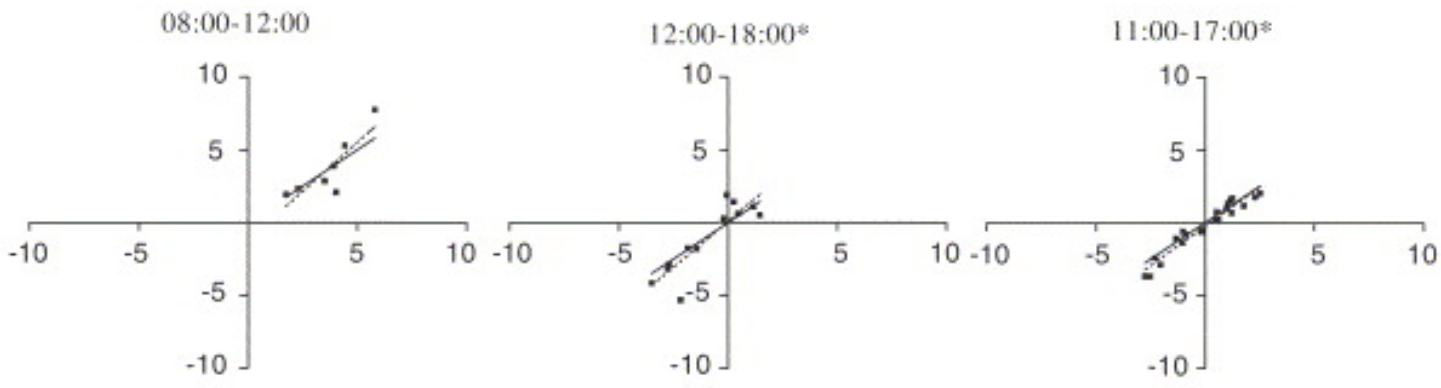

$\Delta \mathrm{T}$ in avoided landscapes

Fig. 5. Comparisons between the temperature changes occurring in landscapes preferred by elephants with those avoided. The solid line represents our null model if no difference occurred between the two. The stippled line represents the actual linear relationship between preferred and avoided landscapes. Differences were observed between hours marked with $(*)$. 
During the cold season in Kafue, between 10:00 and 14:00 only, preferred landscapes warmed slower than avoided ones when temperatures changed at a rate greater than 3$5^{\circ} \mathrm{C}$ per hour (slope: $t=6.3, \mathrm{df}=10, P<0.001$; intercept: $t=7.02, \mathrm{df}=10, P<0.001$ ). At hourly rates of change below this, preferred landscapes changed faster than avoided ones. Throughout the night, preferred landscapes changed slower than landscapes elephants avoided (slope: $t=6.11, \mathrm{df}=33, P<0.001$; intercept: $t=4.08, \mathrm{df}=33, P<0.01$ ).

In Kafue, during the hot dry season no differences occurred in temperature changes between preferred and avoided landscapes for either individual in the morning (08:0012:00). Between 12:00 and 18:00 for cows only, preferred landscapes changed at a slower rate than those they avoided (slope: $t=2.53, \mathrm{df}=10, P<0.05$ ). We found no differences between preferred and avoided landscapes between 18:00 and 00:00. Landscape preference occurred between 11:00 and 17:00 only, in Zambezi during the hot dry season. Preferred landscapes warmed slower but cooled faster than the landscapes they avoided (intercept: $t=2.3, \mathrm{df}=20, P<0.05$ ).

\section{Discussion}

One expects larger mammals to distribute themselves more evenly across heterogeneous landscapes than smaller mammals (du Toit and Owen-Smith, 1989). Elephants should represent the most "supreme examples of habitat generalists" (Owen-Smith, 1988). Elephants do use landscapes selectively, however, (e.g. Omphile and Powell, 2002) and many variables may determine this selectivity (Ruggiero and Fay, 1994; Dublin, 1996; Verlinden and Gavor, 1998; De Boer et al., 2000; Stokke and du Toit, 2002). Until now, no studies have examined whether the thermal environment might influence such selection.

Elephants show preferences for particular landscapes. For example, during a specific season they may prefer closed woodlands to open areas because the former provides more food. During similar time-periods, elephants may also select for landscapes where the rates of change in temperatures suit their thermoregulatory needs. In this instance, it may be difficult to distinguish landscape selection from selection for the rates of change in temperature. If temperatures in preferred landscapes do not change in a similar pattern 
as observed for our independent temperature selection analyses, then we infer that selection for the rates of change in temperature is independent of landscape preference. Generally, animals are likely to gain heat when it is hot and lose heat when it is cold. By choosing landscapes where temperatures rapidly increase or decrease elephants have a chance to manipulate the rate at which they exchange heat with their environment. In the cold season, elephants may select for rates of change in temperature as opposed to some other variable associated with their preferred landscapes. During the day when temperatures were on the increase, elephants used landscapes where temperatures increased more slowly than in those landscapes not selected. So, in terms of heat exchange, when ambient temperatures were above the elephant's surface temperatures, elephants gained heat at a slower rate from their environment than had they chosen other available rates of change. Conversely, during ambient temperatures below that of their skin temperatures, they selected landscapes to maximize heat loss to the environment. In the hot dry season, although elephants in both sites selected for rates of change in temperatures to some degree, our results show that these characteristics link to preferred landscapes. In this instance, unlike the cold season during the day, we infer that elephants selected for some factor(s) associated with the landscapes and not actual rates of change in temperature.

The ability of elephants to control their skin temperature is important for heat exchange (Phillips and Heath, 1995). During the hot dry season, solar radiation during the day is extremely high and can, therefore, increase skin temperatures significantly. Elephants can potentially reduce this additional heat load from the sun by seeking shade. During the cold season, solar radiation is not such a limiting factor. Consequently, controlling skin temperatures may not be as important as in the hot dry season when solar radiation is high. As a result, the importance of other variables such as canopy cover may override the thermal benefits an elephant will receive compared to rates of temperature change alone.

Throughout the night, cows from both sites and in both seasons selected landscapes where temperature changed slower, suggesting a more constant thermal environment. Bulls selected more constant thermal environments in the cold dry season only. They preferred landscapes that cooled slower than ones they avoided. Despite this, our results 
suggest that individuals selected for changes in temperature and not specific landscapes per se. Due to their large size, low temperatures throughout the night should be well within a comfortable range of temperatures for elephants (Hiley, 1975; McNab, 1983; Williams, 1990). As such, we expect that elephants would select environments where temperatures are more constant so that the physiological effort of maintaining a constant body temperature in a fluctuating thermal environment is reduced.

Differences between the sexes in the selected rates of change in temperature occurred during the hot dry season only. Just after sun down, cows from both sites selected landscapes that cooled faster. Since elephants should lose heat to their environment during cool temperatures, by selecting landscapes where temperature cooled down faster, they should lose heat to the environment at a faster rate. Although Kafue cows preferred open areas during this time, the rate at which temperatures changed in this landscape alone did not promote heat loss. As a result, we infer that cows used a combination of landscapes leading to selection for the rates of change. During this same period, bulls did not select either temperature changes or landscapes. Instead, bulls appeared to promote heat loss later on throughout the night.

Although our results suggest that elephants do select for the rate at which temperatures change, we cannot ignore that they possibly selected for some unknown variable perhaps associated with the rates of change in temperature. However, we suggest that the thermal characteristics of landscapes, including the rates of change in temperature, provide a thermal benefit to elephants by facilitating heat exchange with their environment. If this is indeed the case, then our nocturnal hot dry season results are surprising as elephants used environments to cool down faster and not to conserve heat as expected. We suggest that if elephants are indeed choosing landscapes based on the rates of change in temperature, then their underlying selections are driven by the several thermal advantages they may incur.

Our findings can be explained is in terms of "adaptive heterothermy", a process where heat is stored during the day and then offloaded during the cool of the night. Heterothermy has been suggested for many ungulates such as eland (Taylor and Lyman, 1967) and giraffe (Langman and Maloiy, 1989). The idea that heat may be stored by elephants (Wright and Luck,1984; Langman, cited as personal communication in Phillips 
and Heath, 1992) has not been tested. However, Mitchell et al. (2002) argued that earlier studies failed to meet all the criteria of adaptive heterothermy and as such, the camel is the only species (Schmidt-Nielson et al, 1975) for which the phenomenon has been illustrated so far. Heterothermy, therefore, still has to be illustrated for the elephant and until then remains no more than a speculation.

As an alternative to heat storage, it may be that differences occurring across seasons in the diet composition and feeding activities of elephants (Ruggiero, 1992) may also influence their landscape utilization and hence the differences we observed between seasons. However, the nature of how these seasonal foraging differences are likely to influence their landscape selection in terms of obtaining thermal benefits, requires further investigation. While each explanation seems reasonable, we are not in a position to rule out alternative hypotheses. Further studies on the eco-physiology of elephants are needed to determine whether they are indeed selecting landscapes based on the rates of change in temperature.

Both sexes used landscapes that promoted heat loss but when this occurred, differed between the two. Juveniles should lose heat faster in colder temperatures since they are smaller (Schmidt-Nielson, 1984). As a result, cows may select to offload heat during the warmer temperatures of the late evening to facilitate the thermal needs of juveniles. Bulls do not incur the limitations imposed by juveniles, allowing them to offload heat gradually throughout the night.

\section{Conclusion}

Our study suggests that the rate at which ambient temperatures change may play a role in elephant landscape selection. We further propose that canopy cover can also influence selection for landscapes. By selecting for variables associated with canopy cover and rates of change in temperature, elephants can incur thermal benefits that enable them to maintain a certain body temperature. Hence, while we acknowledge that food and water requirements are important in determining landscape selection in elephants, we propose that complex physiological needs should also be considered, specifically, their thermal physiology. 


\section{References}

Buss and Wallner, 1965 I.O. Buss and A. Wallner, Body temperature of the African elephant, J. Mammal. 46 (1965), pp. 104-107.

Cole, 1986 M.M. Cole, The Savannas: Biogeography and Geobotany, Academic Press, London (1986).

De Boer et al., 2000 W.F. De Boer, C.P. Ntumi, A.U. Correia and M. Mafuca, Diet and distribution of elephant in the Maputo Elephant Reserve, Mozambique, Afr. J. Ecol. 38 (2000), pp. 188-201.

Dublin, 1996 H.T. Dublin, Elephants of the Masai Mara, Kenya: seasonal habitat selection and group size patterns, Pachyderm 22 (1996), pp. 25-35.

Dunham, 2003 Dunham, K.M., 2003. Aerial survey of elephants and other large herbivores in the Zambezi heartland (Zimbabwe, Mozambique and Zambia). A Report for the African Wildlife Foundation.

du Toit and Owen-Smith, 1989 J.T. du Toit and N. Owen-Smith, Body Size, population metabolism and habitat specialization among large African herbivores, Am. Nat. 133 (1989), pp. 736-740.

Guldemond et al., 2005 R.A.R. Guldemond, E.R. Lehman, S.M. Ferreira and R.J. van Aarde, Elephant numbers in Kafue National Park, Zambia, Pachyderm 39 (2005), pp. 5057.

Hiley, 1975 P.G. Hiley, How elephants keep their cool, Nat. Hist. 84 (1975), pp. 34-41. Hoare, 1999 R.E. Hoare, Determinants of human-elephant conflict in land-use mosaic, $J$. Appl. Ecol. 36 (1999), pp. 689-700.

Houston et al., 2001 D.C. Houston, J.D. Gilardi and J. Hall, Soil consumption by elephants might help minimize the toxic effects of plant secondary compounds in forest browse, Mammal Rev. 31 (2001), pp. 249-254.

Japan International Cooperation Agency (JICA), 1999 Japan International Cooperation Agency (JICA), 1999. Kafue National Park General Management Plan. Final Report. Langman and Maloiy, 1989 V.A. Langman and G.M.O. Maloiy, Passive obligatory heterothermy of the giraffe, J. Physiol. (London) (1989), p. 415.

McNab, 1983 B.K. McNab, Energetics, body size and the limits to endothermy, J. Zool. London 199 (1983), pp. 1-29. 
Mitchell et al., 2002 D. Mitchell, S.K. Maloney, C. Jessen, H.P. Laburn, P.R. Kamerman, G. Mitchell and A. Fuller, Adaptive heterothermy and selective brain cooling in arid zone mammals, Comp. Biochem. Phys. B. 131 (2002), pp. 571-585.

Ndumo, 1977 Ndumo, N.G., 1977. The effects of micro-meteorology and status of vegetation on the diurnal behaviour of free-ranging elephants in Tsavo National Park East, Kenya. Seminar on vegetation studies in Tsavo National Park.

Nellemann et al., 2002 C. Nellemann, R.M. Stein and L.P. Rutina, Links between terrain characteristics and forage patterns in elephants (Loxodonta Africana) in northern Botswana, J. Trop. Ecol. 18 (2002), pp. 835-844.

Neu et al., 1974 C.W. Neu, C.R. Byers and J.M. Peek, A technique for analysis of utilization availability data, J. Wildlife Manage. 38 (1974), pp. 541-545.

Omphile and Powell, 2002 U.J. Omphile and J. Powell, Large ungulate habitat preference in Chobe National Park, Botswana, J. Range Manage. 55 (2002), pp. 341-349.

Owen-Smith, 1988 N.S. Owen-Smith, Megaherbivores: Implications for Very Large Body Size, Cambridge university press, Cambridge (1988).

Phillips and Heath, 1992 P.K. Phillips and J.E. Heath, Heat exchange by the pinnae of the African elephant, Comp. Biochem. Phys. A 101 (1992), pp. 693-699.

Phillips and Heath, 1995 P.K. Phillips and J.E. Heath, Dependency of surface temperature regulation on body size in terrestrial mammals, J. Therm. Biol. 20 (1995), pp. 281-289.

Ruggiero, 1992 R.G. Ruggiero, Seasonal forage utilization by elephants in central Africa, Afr. J. Ecol. 30 (1992), pp. 137-148.

Ruggiero and Fay, 1994 R.G. Ruggiero and J.M. Fay, Utilization of terminitarium soils by elephants and its ecological implications, Afr. J. Ecol. 32 (1994), pp. 222-232.

Schmidt-Nielson, 1984 K. Schmidt-Nielson, Scaling: Why is Animal Size so Important?, Cambridge University Press, Cambridge (1984).

Schmidt-Nielson et al., 1975 K. Schmidt-Nielson, B. Schmidt-Nielson, S.A. Jornum and T.R. Haupt, Body temperature of the camel and its relation to water economy, Am. J. Physiol. 188 (1975), pp. 103-112.

Scholes and Walker, 1993 R.J. Scholes and B.H. Walker, An African Savanna: Synthesis of the Nylsvley Study, Cambridge University Press, Cambridge (1993). 
Stokke and du Toit, 2002 S. Stokke and J.T. du Toit, Sexual Segregation in habitat use by elephants in Chobe National Park, Botswana, Afr. J. Ecol. 40 (2002), pp. 360-371. Taylor and Lyman, 1967 C.R. Taylor and C.P. Lyman, A comparative study of the environmental physiology of an East African antelope, the eland, and the Hereford steer, Physiol. Zool. 40 (1967), pp. 280-295.

Tracy, 1972 C.R. Tracy, Newton's law: its application for expressing heat losses in homeotherms, Bioscience 22 (1972), pp. 656-659.

Verlinden and Gavor, 1998 A. Verlinden and I.K.N. Gavor, Satellite tracking of elephants in Northern Botswana, Afr. J. Ecol. 36 (1998), pp. 105-116.

Williams, 1990 T.M. Williams, Heat transfer in elephants: thermal partitioning based on skin temperature profiles, J. Zool. Lond. 222 (1990), pp. 235-245.

Wright and Luck, 1984 P.G. Wright and C.P. Luck, Do elephants need to sweat?, South Afr. J. Zool. 19 (1984), pp. 270-274.

Corresponding author. Tel.: +27 1242027 53; fax: +27 124204523 . 